\title{
Article \\ Brunelleschi's Dome: A New Estimate of the Thrust and Stresses in the Underlying Piers
}

\author{
Mario Como
}

Citation: Como, M. Brunelleschi's Dome: A New Estimate of the Thrust and Stresses in the Underlying Piers. Appl. Sci. 2021, 11, 4268. https:// doi.org/10.3390/app11094268

Academic Editor: Claudia Cennamo

Received: 21 March 2021

Accepted: 28 April 2021

Published: 8 May 2021

Publisher's Note: MDPI stays neutral with regard to jurisdictional claims in published maps and institutional affiliations.

Copyright: (C) 2021 by the author. Licensee MDPI, Basel, Switzerland. This article is an open access article distributed under the terms and conditions of the Creative Commons Attribution (CC BY) license (https:/ / creativecommons.org/licenses/by/ $4.0 /)$.
Department of Civil Engineering and Computer Science, University of Rome "Tor Vergata", 00133 Rome, Italy; como@ing.uniroma2.it; Tel.: +39-335-692-9586

\begin{abstract}
The paper deals with the insurgence of the thrust, together with its valuation, in masonry domes, giving special attention to the Brunelleschi's Dome in Florence. After a recalling of the kinematical approach in the context of the Heyman masonry model, the thrust of Brunelleschi's Dome is estimated as the maximum of the set of all the kinematical ones. Comparisons are made with other valuations made by the usual, but less accurate, statical approach. The knowledge of the thrust allows an evaluation of the stresses acting in the supporting piers: their base sections are all compressed, with level stresses sufficiently low. This result shows the extraordinary conception of Filippo Brunelleschi's Dome and the favorable design of the pillar sections and of the drum positioning, due, perhaps, to Arnolfo di Cambio or to the succeeding Masters.
\end{abstract}

Keywords: domes; masonry; no tension material; Brunelleschi's Dome; minimum thrust; kinematical approach; stress analysis

\section{Introduction}

This article aims to study the statical behavior of Brunelleschi's Dome in Florence which, for its significance, since 1982 has been one of the UNESCO World Heritage sites. The research is developed by means of the limit analysis approach according to the simple no tension Heyman model [1] of the masonry material and in the context of the consequent mathematical formulation given in [2,3]. The first aim of this article is the thrust estimate of the Dome, required to assess the actual state of safety of the monument. This subject is strongly debated. Many studies have been performed by using numerical approaches [4-12] that require the use of models involving complex convergence analysis and heavy computational problems [5].

An alternative to these complex numerical approaches is the assessment of statics of the masonry dome according to the limit analysis, founded on the masonry Heyman no tension model [13]. In spite of the simplicity of this last approach, all the main aspects of the masonry dome's behavior are taken into account: the dome is divided into slices, in fact, with the development of meridian cracks due to the masonry weakness to sustain hoop stresses; the dome thrust takes place and radial settlement displacements occur in the drum; the dome adapts itself to the settlement and deforms with a mechanism activating the minimum thrust.

This complex picture of statical events occurring in masonry domes, with their passage from the initial membrane state of stress to that of the cracked behavior, is fully interpreted by the limit analysis, particularly in the context of the kinematical approach that directly employs the deformation modes and the mechanisms, in order to define, by means of the virtual work equation, the equilibrium of no tension structures.

The novelty of the paper lies in the application of the kinematical approach that directly pursues the insurgence of the thrust following the occurrence of the meridian cracking and the accompanying settlement mechanism of the Dome. In this context, the thrust is assessed by checking the maximum of all the kinematical thrusts, according to previous results obtained by the author $[14,15]$. This approach is not well known and rarely applied, 
whereas less accurate graphical procedures, with the construction of funicular polygons of minimum thrust, are commonly used. For this reason, the article first recalls the mechanical basis of this approach, by reporting the proof of the theorem of the maximum kinematical thrust $[14,15]$. Then, after a brief description of the actual damage state, the evaluation of the thrust of Brunelleschi's Dome is achieved. This analysis improves a previous valuation of the thrust obtained by means of the statical approach [16] (pp. 242-271), that obtained a value of the thrust about $15 \%$ lower than the value given here.

The knowledge of the actual thrust of the Dome is of fundamental importance to obtain a sound stress analysis of the various structural components of the monument and it reveals the presence of a safe state of stress in the supporting piers. The new study of the thrust transfer, together with the conveyance of the various vertical loads, from the Dome to the underlying drum and to the pointed arches, as far as to the supporting piers, proves to be particularly simple, compared to the much more complex valuations developed by means of the application of finite elements techniques.

The results obtained point out not only the extraordinary genius of Brunelleschi but also the smart design of the drum and of its supporting pillars, due perhaps to Arnolfo di Cambio or to the succeeding Masters such as Talenti, Lapo di Ghini and Neri di Fioravanti.

\section{The Dome}

Unlike most cupolas which, like the Pantheon, are hemispherical in profile, the vault of Santa Maria del Fiore is a pointed dome.

The Dome intrados, sectioned by vertical planes passing through opposite corners, is a circular arch. Each of these eight arches is called a "pointed fifth" and inscribes an angle of about $60^{\circ}$ with the center of the circle. The radius of a pointed fifth is equal to $4 / 5$ of the distance spanning the internal corners of the octagonal annulus, i.e., equals $4 / 5^{\prime} 77$ arms $=$ $4 / 5^{\prime} 44.97 \mathrm{~m}=35,976 \mathrm{~m}(1 \mathrm{arm}=0.584 \mathrm{~m})$. These eight arches, converging upwards in the center, form the groin ribs of the Dome's intrados [17-20].

The Dome is an octagonal cloister vault made up of four interpenetrating barrel vaults. There are eight webs and their surface is produced by horizontal straight lines extending from the octagon sides. Each of the eight webs spans two adjacent corners, or groin ribs, the "speroni d'angolo". Each web is composed of two shells stiffened by two median ribs, called "speroni mediani", connected to the groin ribs by nine horizontal arches [17,20]. This stiffening system connects the external and the internal shells tightly together so that the composite vault behaves like a single solid dome. The internal masonry pattern differs from the external shape of the dome and, surprisingly, presents a rotational structure.

\section{Crack Patterns in the Dome}

Documentation of the first cracks detected on the Dome dates back to the year 1639, when meridian cracks on the intrados of the internal shell were first noticed. At the end of the seventeenth century, according to Nelli and Viviani, these cracks cut across the whole drum [21]. A history of the gradual damage detected has been reported in [22].

The largest cracks on the Dome intrados were surveyed by Blasi and Ceccotti in 1984 [23]. Cracks have developed on the intrados along the meridians in the middle of the webs placed over the four cathedral pillars. No cracking has been detected along the groin ribs. The largest cracks, averaging $5-6 \mathrm{~cm}$ in width, run along the inner shell on the north-eastern and south-eastern webs.

From the crown down to a co-latitude angle of about $25^{\circ}$, the Dome webs over the pillars are intact, but are separated thereafter into slices by meridian cracks. Monitoring systems actually control the crack evolution over time [22,24,25].

The detected crack pattern is that of a revolution dome, due to Brunelleschi's circular arrangement of the brick courses, so all the eight webs transmit their thrusts equally to the underlying drum. 


\section{Reasons of the Typical Cracking in Masonry Domes}

Cracking is generally delayed in masonry domes. Cracks occur in a masonry arches as soon as stresses exceed the weak adhesion strength between the stones and the mortar. Compressive forces and shears continue to spread across the hinges that can form in the sections; the friction cannot oppose the development of cracks. On the contrary, in masonry domes, the friction increases their tensile strength, as Figure 1 shows.

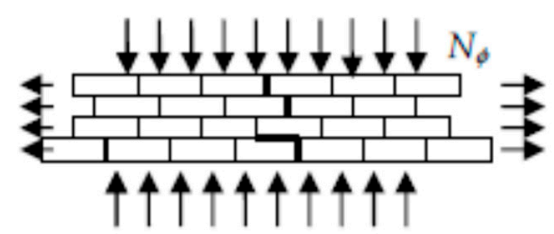

Figure 1. Friction increasing due to meridian compressions.

At the cracking occurrence, the dome starts to widen and the circular courses have to slip one over the other. The friction strength produced by meridian compression $N_{\varphi}$ opposes this slipping. Thus, the masonry's tensile strength is actually increased by the meridian compression. Humidity, which generally penetrates slowly into masonry, weakens the mortar and reduces this friction strength over time. These considerations explain why cracks generally occur only many years after the end of a dome's construction. The history of cracking of many famous vaults and domes bears this out. For example, both the domes of St Peter's in Rome and Santa Maria del Fiore in Florence began to crack at least fifty years, or more, after their completion [16] (p. 209).

The dome cracks when the tension stress in the hoop rings near the springing reach the limit value of the masonry's weak tensile strength. The initial membrane equilibrium is thereby lost and meridian cracks spread up the dome along a band much higher than that subjected to the hoop stresses in the initial membrane equilibrium. The cracked dome tends to open wide and breaks up into slices that behave as independent pairs of semi-arches leaning on each other (Figure 2).

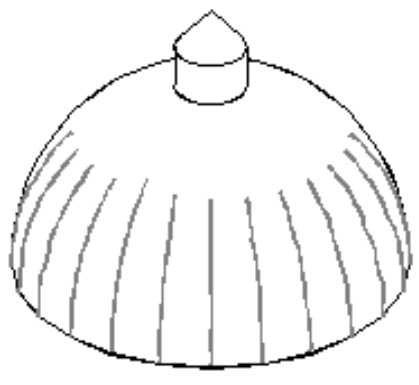

(a)

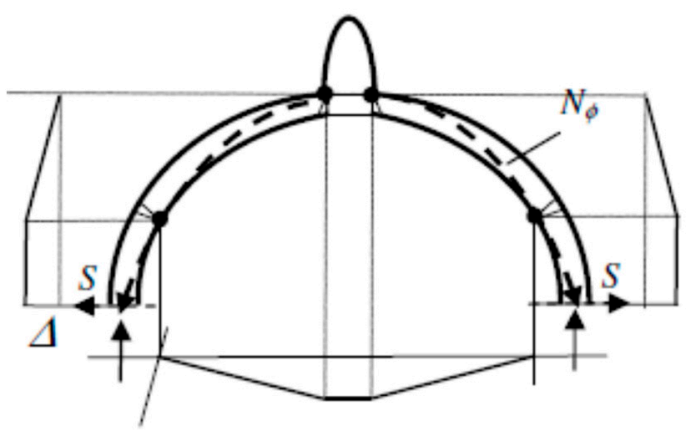

(b)

Figure 2. (a) Typical meridian cracks; (b) dome slice with increased span due to springer setting.

Cracking brings about a profound change in the dome's statics. The hoop stresses in the cracked zone vanish and stresses $N_{\varphi}$, before acting along the slices' center lines, are no longer able to ensure equilibrium. The pressure surface thus tilts towards the horizontal and deviates away from the central surface of the dome. Only a small compressed cap at the top of each slice will be subjected to the thrusting action transmitted, by the other slices, all the way to the springers.

The emergence of thrust in the dome represents the most consequential outcome of meridian cracking in typical round masonry domes [13] (pp. 35-39], [16] (pp. 200-224).

When cracks are barely perceptible, only elastic unloading of the dome rings has occurred. In the presence of numerous broader cracks, on the other hand, the widening of 
the drum will be the main factor responsible for the dome's deformation. Loaded by the dome's thrust, the drum deforms and slightly splays. Meridian cracks in the dome thus continue in the drum. A small widening in the dome span occurs. The dome slices adapt themselves to this deformation, freely following the spreading of the dome. They develop a settlement mechanism. This picture describes the occurrence of cracking as it happened in Brunelleschi's Dome.

\section{Some Brief Examinations of the Statics of Masonry Structures}

Many studies use advanced outlines of the geometry of the Dome but use questionable models of the material. The linear elastic model sometimes is assumed and the actual crack patterns are introduced in the initial geometry of the Dome without following the gradual crack propagation. Other studies use a constitutive model taken from the study of other materials, particularly of concrete.

In contrast to the large variety of approaches that, with different assumptions, try to analyze the statics of the Dome [4-12], there are the thrust assessments that move in the context of the limit analysis, founded on the masonry Heyman no tension model. We now recall the basic simple principles of the statics of masonry constructions, limited to the simpler case of unidimensional structures, to which the sliced cracked domes revert. The following constitutive assumptions were formulated by Heyman [1]:

\section{i. masonry is incapable of withstanding tensions \\ ii. masonry has infinite compressive strength \\ iii. elastic strains are negligible \\ iv. sliding cannot occur because masonry has infinite shear strength}

In this framework, the single resistant cell of a masonry structural element, as, for example, the slices of a dome, is composed of two ideal rigid bricks, of height $h$, loaded by eccentric axial load and shear, as shown in Figure 3.

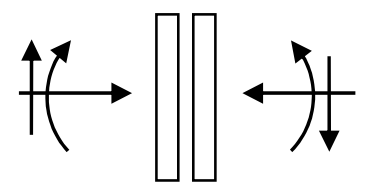

Figure 3. The single resistant masonry cell.

Only compressive stresses are consistent. Thus, the eccentricity of the axial load

$$
e=M / N
$$

will respect the inequality

$$
-h / 2 \leq e \leq h / 2
$$

Assumption iv prohibits sliding. Consequently, the shear force $T$ is involved only in the equilibrium between the two ideal bricks. Any strain of the unit resistant cell will be either zero or the detachment strain

$$
\mathbf{E}=\left[\begin{array}{c}
\phi \\
\Delta \\
0
\end{array}\right]
$$

where the third strain component is zero because, according to assumption $i v$, no sliding can occur. Admissible stress and strain vectors are shown in Figure 4. 

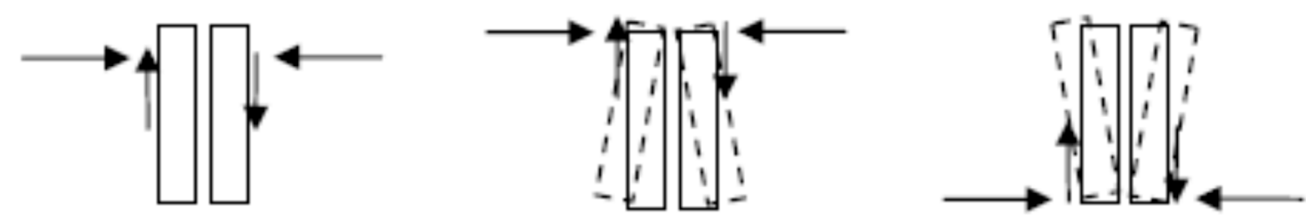

Figure 4. Stresses not producing or producing detachment strains in the cell.

The set of all allowable stresses and strains $\Sigma$ and $\mathrm{E}$ are, respectively, denoted by $\mathrm{V}$ and $\mathrm{Y}$. The direct consequence of the pressing and expanding features of $\boldsymbol{\Sigma}$ and $\mathbf{E}$ is the following fundamental inequality $[2,3]$

$$
\boldsymbol{\Sigma} \cdot \mathbf{E} \leq 0, \forall \boldsymbol{\Sigma} \in \mathrm{Y}, \forall \mathbf{E} \in \mathrm{V}
$$

A hinge in the ideal cell takes place when the strains sketched in Figure 4 occur.

When, in a masonry structure, a sufficient number of hinges occurs, the arch, or any other structure, can become deformed according to a displacement field $\mathbf{u}$, called the mechanism. The set of all the mechanisms is denoted by $M$.

The admissible equilibrium of masonry structures is governed by the principle of virtual work that takes, for unidimensional masonry elements, the typical form expressing the equality between internal and external virtual work [16] (pp. 79-82)

$$
<\mathbf{p}, \delta \mathbf{u}>=<\mathbf{\Sigma}, \delta \mathbf{E}>\quad \forall \delta \mathbf{u} \in M
$$

coupled to the admissibility condition on the stresses $\Sigma$ and the virtual strains $\delta \mathbf{E}(\delta \mathbf{u})$

$$
<\Sigma, \delta \mathbf{E}>\leq 0
$$

\section{Settlement State. Allowable Equilibrium}

Let us consider a masonry structure, for instance, an arch or a dome, under the loads $g$, representative of the weight. The structure is in equilibrium at the configuration $C_{i}$ under the loads $g$ and the corresponding internal stresses $\Sigma_{i}$. A slight settlement of the external constraints of the structure now takes place, as shown, in the case of the arch, in Figure 5.

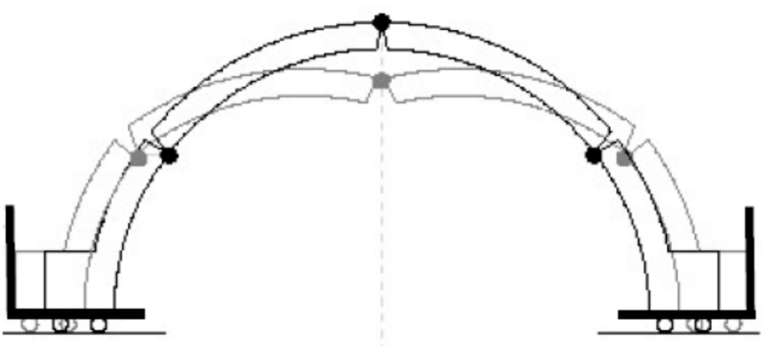

Figure 5. Settlement of the arch.

The arch changes its pressure line and adapts itself to the settlement deformation with a mechanism and follows the displacements of its springers. Let $C_{s}$ be the configuration of the arch after the settlement. The displacement field that moves the arch from $C_{i}$ to $C_{S}$ is the settlement mechanism $\mathbf{v}_{s}$.

Changes of internal stresses occur in the change from $C_{i}$ to $C_{s}$. The initial stresses $\Sigma_{i}$, allowable and in equilibrium with the loads $\mathbf{g}$, change into

For instance, in the case of the settled arch, the pressure line changes from $\pi_{\mathrm{i}}$ to $\pi_{\mathrm{s}}$. Consequently, the horizontal component of the reaction of the settled constraint changes from $\mu_{\mathrm{i}} \mathrm{r}$ to $\mu_{\mathrm{s}} \mathrm{r}$. 
We can release the structure, removing the settled constraint, by applying the corresponding reaction of the canceled constraint (Figure 6). Making reference to the released structure, let $M^{*}$ be the set of all the mechanisms of the structure with the removed constraint.

The structure follows the settlement displacement without any opposition. In the case of the above settled arch, the pressure curve $\pi_{\mathrm{s}}$ will pass through the hinges of the settlement mechanism $v_{s}$. No work of the internal stresses $\Sigma_{S}$ will be made for the settlement strains. Thus, at the settlement state

$$
<\Sigma_{s}, \mathbf{E}\left(\mathbf{v}_{S}\right)>=0
$$

showing that, in the settled structure, the pressure line passes through the hinges of the settlement mechanism. In the released structure, the external loads are the loads $\mathrm{g}$ and the reactions $\mu_{s} \mathbf{r}$, if $\mathbf{r}$ is the reaction corresponding to a unitary value of the multiplier $\mu$. The released structure is in an allowable equilibrium state. Consequently, the following equation of the principle of virtual works holds:

$$
<\mathbf{g}, \delta \mathbf{u}>+\mu_{s}<\mathbf{r}, \delta \mathbf{u}>=\left\langle\boldsymbol{\Sigma}_{s}, \delta \mathbf{E}>\quad \forall \delta \mathbf{u} \in M *\right.
$$

for any mechanism $\delta \mathbf{u}$ of the released structure. Consequently, from (9), taking $\delta \mathbf{u}=\mathbf{v}_{\mathcal{S}}$, because of (8), we get

$$
<\mathbf{g}, \mathbf{v}_{s}>+\mu_{s}<\mathbf{r}, \mathbf{v}_{s}>=0
$$

The weight $\mathbf{g}$ pushes against the settled constraint. These loads $\mathbf{g}$ thus make positive work along the settlement mechanism $\mathbf{v}_{\mathrm{s}}$.

$$
<\mathbf{g}, \mathbf{v}_{s}>>0
$$

On the contrary, the thrust $\mu_{\mathrm{s}} \mathbf{r}$ is resisting and, according to (10) and (11), we get

$$
\mu_{s}<\mathbf{r}, \mathbf{v}_{s}><0
$$

Conditions (8)-(12) define the settlement state.

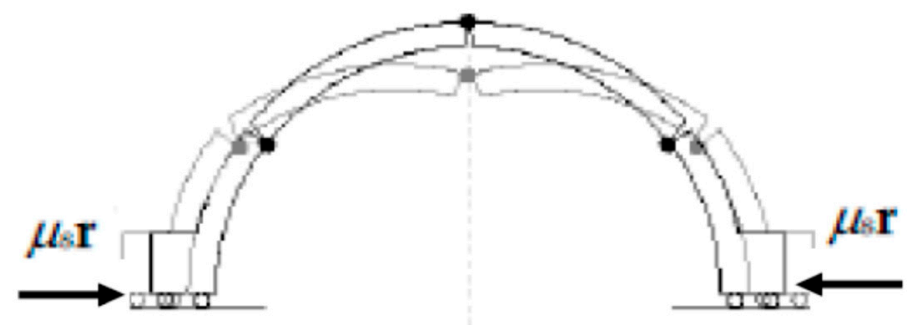

Figure 6. The released arch.

\section{Minimum Thrust}

Let us consider the released structure, loaded also by the reaction of the settled constraint. Let us choose any stress $\Sigma$, statically admissible, i.e., compressive and in equilibrium with the loads. The statically allowable thrust

$$
\mu \mathbf{r}(\Sigma)
$$

will correspond to the chosen statically allowable stress $\Sigma$. It is well known that the actual thrust in the settled state is the minimum among all the statically admissible thrusts (13):

$$
\mu_{S}=\operatorname{MIN} \mu(\boldsymbol{\Sigma}) \quad \boldsymbol{\Sigma} \in Y
$$

This statement, universally accepted, extends the well-known property of the masonry settled arch to any structure. In the state of minimum thrust, the pressure line of the arch, 
that takes the maximum slope at the springers, corresponds to an arch having minimum span and maximum sag, as shown by Coulomb [26] and Heyman [27]. The extension of this statement to any structure with a settling constraint was proven in [14,15], transferring these concepts into a mathematical framework.

In this context, the minimum thrust of a dome is generally obtained using the statical approach, by constructing sequences of funicular polygons of the loads and searching among them for the allowable pressure line with the maximum slope at the springers. Alternatively, the minimum thrust, or more generally, the minimum reaction of the settled constraint, can be obtained as follows.

\section{The Kinematical Approach}

This approach is founded on the following:

Theorem 1. The settlement factor $\mu_{s}$ is the maximum of the kinematical multipliers $\lambda(v)$ for any displacement $v$ varying in the set $M^{*}$ of all the mechanisms [14,15].

Proof. Let us consider in the released structure of any displacement mechanism

$$
\mathbf{v} \in M *
$$

that can represent the occurred settlement. Consequently, according to (11), along the chosen displacement

$$
<\mathbf{g}, \mathbf{v}>>0
$$

Let us consider the kinematical multiplier $\lambda$ of the reaction $\mathbf{r}(\mathbf{v})$ of the settled constraint, satisfying the equilibrium along $\mathbf{v}$

$$
<\mathbf{g}, \mathbf{v}>+\lambda<\mathbf{r}, \mathbf{v}>=0
$$

that is

$$
\lambda(\mathbf{v})=-\frac{\langle\mathbf{g}, \mathbf{v}\rangle}{\langle\mathbf{r}, \mathbf{v}\rangle}, \mathbf{v} \in M *
$$

The quantity $\lambda \mathbf{r}(\mathbf{v})$ is defined as the kinematical reaction of the settled constraint. Consequently, according to (16) and (17),

$$
<\mathbf{r}, \mathbf{v}><0
$$

The so defined thrust

$$
\lambda \mathbf{r}(\mathbf{v})
$$

is thus associated with the chosen settlement mechanism $\mathbf{v}$. Let us assume $\delta \mathbf{u}=\mathbf{v}$ in the virtual Equation (9) expressing the allowable equilibrium in the settlement state between the external loads $\mathbf{g}$ and $\mu_{\mathrm{s}} \mathbf{r}$ and the internal stresses $\boldsymbol{\Sigma}_{\mathrm{s}}$. We get

$$
<\mathbf{g}, \mathbf{v}>+\mu_{s}<\mathbf{r}, \mathbf{v}>=\left\langle\boldsymbol{\Sigma}_{s}, \mathbf{E}(\mathbf{v})\right\rangle
$$

Subtracting (17) from (21) we get

$$
\left(\mu_{s}-\lambda(\mathbf{v})\right)<\mathbf{r}, \mathbf{v}>=<\boldsymbol{\Sigma}_{s}, \mathbf{E}(\mathbf{v})>
$$

and, taking into account (6),

$$
<\Sigma_{s}, \mathrm{E}(\mathbf{v})>\leq 0
$$

Consequently

$$
\left(\mu_{s}-\lambda(\mathbf{v})\right)<\mathbf{r}, \mathbf{v}>\leq 0
$$

and, taking into account (19),

$$
\lambda(\mathbf{v}) \leq \mu_{s} \forall \mathbf{v} \in M *
$$


The kinematical multiplier $\lambda(\mathbf{v})$ is never larger than the actual settlement multiplier settlement $\mu_{s}$, the minimum among all the statically allowable stress states $\Sigma$. This $\mu_{s}$ is the maximum of the kinematical multipliers $\lambda(\mathbf{v})$ for any displacement $\mathbf{v}$ varying in the set of all the mechanisms $M^{*}[14,15]$. Thus,

$$
\mu_{s}=\operatorname{MIN} \mu\left(\sum\right)=\operatorname{MAX\lambda }(\mathbf{v})=\operatorname{MAX}\left(-\frac{<\mathbf{g}, \mathbf{v}>}{<\mathbf{r}, \mathbf{v}>}\right), \sum \in \mathbf{Y}, \mathbf{v} \in M *
$$

\section{The Minimum Thrust in the Dome Estimated with the Kinematical Approach}

The occurrence of thrust slices the masonry dome, due to the development of meridian cracks. The thrust deforms the underlying support structures, firstly, the drum, yielding a slight increase in the dome span. Slices follow this deformation and, as described earlier, mobilize a thrust that is the minimum among all the statically allowable ones. Figure 7 sketches the outline of a generic mechanism $\mathbf{v}$ of a dome slice whose base undergoes a slight broadening $\Delta$.

The point $\mathrm{O}$ indicates the position at the intrados of the internal hinge. Figure 7 shows all the quantities involved. The settlement mechanism is represented by the outwards horizontal settling $\Delta(\mathbf{v})$ associated with the chosen mechanism $\mathbf{v}$. The minimum thrust of the dome is evaluated by applying the kinematic procedure. The unknown thrust, that is, the minimum of all statically allowable thrusts, is obtained [16] (p. 286) as the maximum of all the kinematical thrusts

$$
S_{\text {Min }}=\operatorname{Max} S_{k i n}(v)=\operatorname{Max} \frac{<g, v>}{\Delta(v)}
$$

where $\mathbf{v}$ is any settlement mechanism. The work done by loads $\mathbf{g}$ along the displacement $\mathbf{v}$ is given by

$$
<g, \mathbf{v}>=\theta \sum_{i} G_{i}\left(D *-x_{i}\right)
$$

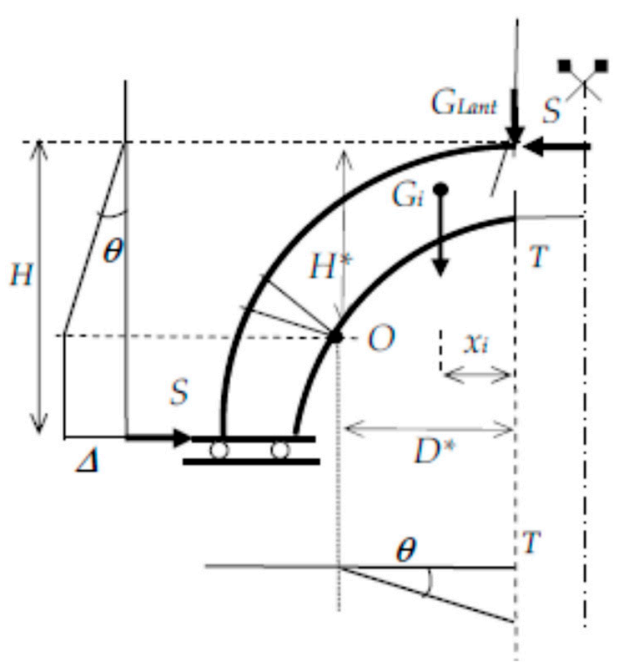

Figure 7. The minimum thrust evaluated via the kinematic approach.

if $D^{*}$ and $x_{i}$ indicate, respectively, the horizontal distances of the hinge $O$ and of the force $G_{i}$ from the vertical alignment $T$, as shown in Figure 7 . Finally, we have

$$
\Delta(v)=\theta H *
$$

where $H^{*}$ is the vertical distance between the internal hinge $\mathrm{O}$ and the extrados of the top section, at the joining of the slice with the lantern. The vertical displacements $v_{i}$ of the 
application points of loads $G_{i}$, representing the weights of the various wedges, are then given by

$$
v_{i}=\left(D *-x_{i}\right) \theta
$$

Thus, we have

$$
S_{k i n}(v)=\frac{\sum_{i} G_{i}\left(D *-x_{i}\right)}{H *}
$$

This approach has been applied by the author to evaluate the thrust of St Peter's in Rome $[28,29]$.

\section{Thrust Estimate of Brunelleschi's Dome}

The thrust of Brunelleschi's Dome has been evaluated with regard to a Dome slice equal to $1 / 8$ of the entire Dome, referring to the single web supported directly by the underlying pier. The outer and the inner shells forming the Dome are strictly connected by ribs and the horizontal arches, so that the vault, despite its complexity, can be accurately described as behaving like a single solid structure.

Making reference to Figure 8 that shows the octagonal horizontal section of the dome, we notice that the meridian sections of the Dome change with the position of the vertical sectioning planes so that the thrust, corresponding to the various slices, will change along the drum. The thrust, on the unit length of the average circle at Dome springing, will thus exhibit the undulating pattern sketched out in Figure 8, in which the middle sections of the webs correspond to the dotted lines.

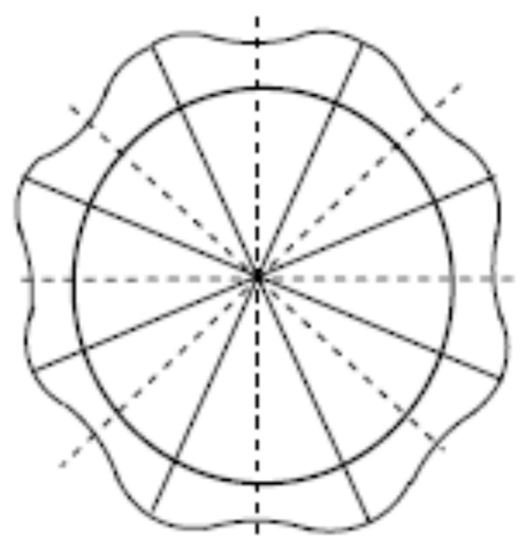

Figure 8. Variation of the thrust along the sections: dotted lines indicate the web centers.

The computation of the thrust of the dome is made by firstly dividing the slice into 31 voussoirs and determining their weights and the positions of their centers with respect to a definite coordinate system, as shown in Table 1 . The unit weight of the masonry voussoirs has been assumed to be equal to $1.85 \mathrm{t} / \mathrm{mc}$. The first voussoir defined by the number 1 corresponds to the voussoir at the crown. The corresponding share of the weight of the lantern is reported in the last row of Table 1.

According to the foregoing calculations, the total weight $G_{s}$ of the slice, evaluated up to the height of the extrados of the drum and taken as $1 / 8$ of the whole dome, including the share of the lantern, equals $3575 \mathrm{t}$.

The maximum kinematic thrust $S_{k i n}(\mathbf{v})$ is found by trials, varying the position of the internal hinge $\mathrm{O}$ along the intrados curve of the slice. Four positions, denoted by 1, 2, 3 and 4 (Figure 9), have been chosen to place the internal hinge at the intratrados of the dome. In Figure 9, the pressure curve, corresponding to the calculation of the minimum thrust performed in [16] (pp. 260-261) by means of the statical approach, is also sketched. We can recognize the approximation of this evaluation due to graphical imperfection in the construction of the sequence of funicular polygons. 


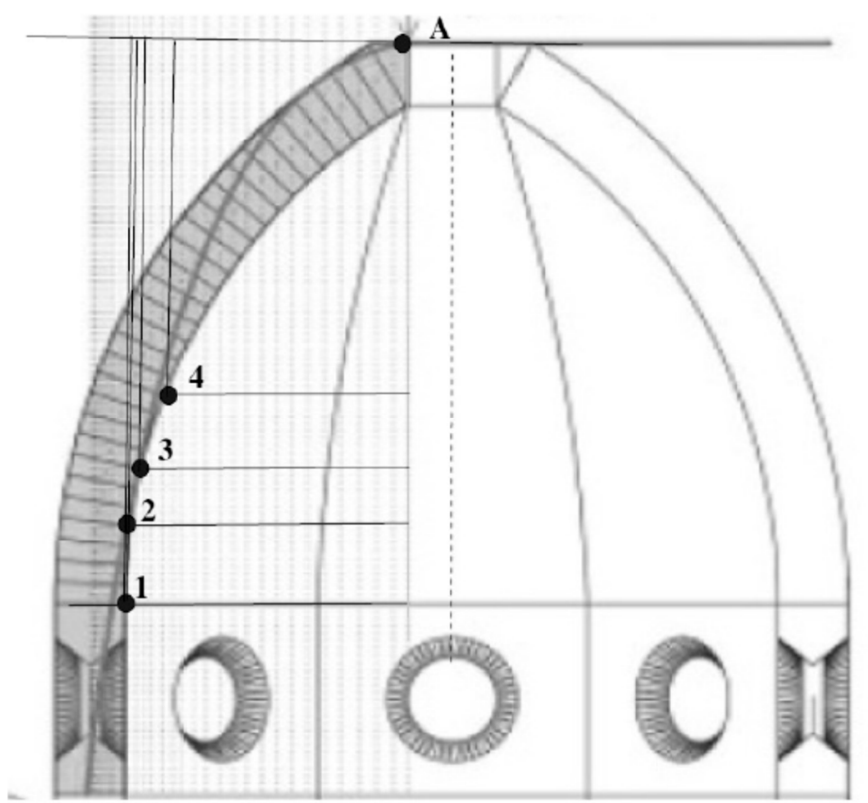

Figure 9. The section of Brunelleschi's Dome with the positions 1, 2, 3, 4 of the considered internal hinge $\mathrm{O}$ of the various chosen settlement mechanisms.

Table 1. Weight of voussoirs and coordinates of their centers.

\begin{tabular}{|c|c|c|c|c|}
\hline Voussoir & Vol. $\mathrm{m}^{3}$ & Weight (t) & $X_{G}(\mathrm{~m})$ & $\mathrm{Y}_{\mathrm{G}}(\mathrm{m})$ \\
\hline 1 & 16.64 & 30.79 & 357.41 & 35.51 \\
\hline 2 & 21.57 & 39.84 & 356.30 & 35.47 \\
\hline 3 & 24.72 & 45.74 & 355.21 & 34.59 \\
\hline 4 & 28.67 & 53.03 & 354.08 & 33.68 \\
\hline 5 & 37.13 & 68.68 & 352.94 & 32.86 \\
\hline 6 & 37.22 & 68.86 & 351.91 & 31.81 \\
\hline 7 & 44.46 & 82.26 & 350.81 & 30.85 \\
\hline 8 & 47.21 & 87.34 & 349.87 & 29.85 \\
\hline 9 & 48.79 & 90.26 & 348.92 & 28.76 \\
\hline 10 & 58.48 & 108.19 & 347.92 & 27.76 \\
\hline 11 & 55.60 & 102.85 & 347.11 & 26.57 \\
\hline 12 & 61.66 & 114.07 & 346.21 & 25.45 \\
\hline 13 & 65.66 & 121.47 & 345.42 & 24.34 \\
\hline 14 & 64.48 & 119.28 & 344.69 & 23.10 \\
\hline 15 & 74.32 & 137.49 & 343.87 & 21.93 \\
\hline 16 & 69.88 & 129.09 & 343.28 & 20.67 \\
\hline 17 & 72.52 & 134.15 & 342.63 & 19.42 \\
\hline 18 & 81.11 & 150.05 & 341.97 & 18.22 \\
\hline 19 & 75.78 & 140.20 & 341.49 & 16.88 \\
\hline 20 & 82.51 & 152.64 & 340.90 & 15.58 \\
\hline 21 & 82.51 & 152.64 & 340.46 & 14.31 \\
\hline 22 & 80.52 & 148.95 & 340.07 & 12.95 \\
\hline 23 & 90.51 & 166.66 & 339.58 & 11.63 \\
\hline 24 & 82.92 & 153.41 & 339.34 & 10.27 \\
\hline 25 & 83.90 & 155.21 & 339.04 & 8.92 \\
\hline 26 & 84.74 & 156.77 & 338.78 & 7.56 \\
\hline 27 & 85.45 & 158.08 & 338.57 & 6.19 \\
\hline 28 & 86.02 & 159.14 & 338.39 & 4.82 \\
\hline 29 & 86.46 & 159.94 & 338.27 & 3.45 \\
\hline 30 & 86.76 & 160.51 & 338.18 & 2.07 \\
\hline 31 & 86.93 & 160.82 & 338.14 & 0.69 \\
\hline Lant. & & 93.75 & 358.41 & 35.75 \\
\hline
\end{tabular}


The maximum kinematic thrust $S_{k i n}(v)$ is found by varying the position of the internal hinge $\mathrm{O}$ along the intrados curve of the slice.

In the following section, four different mechanisms, numbered from (1) to (4), are considered and the corresponding kinematic thrust $S_{k i n}(v)$ is evaluated.

Quantities $D^{*}$ and $H_{i}^{*}(i=1,2,3,4)$ are, respectively, the distances of the internal hinges $(1,2,3,4)$ of the assumed mechanisms from the vertical and the horizontal alignments passing through the top A of the slice (Figure 9).

Table 2 develops the calculation of the kinematical thrusts according to the various settlement mechanisms corresponding to the chosen four positions of the internal hinge $\mathrm{O}$.

Table 2. Calculation of the kinematical thrusts.

\begin{tabular}{|c|c|c|c|c|c|}
\hline V. & $G_{i}$ & $G_{i}\left(D^{*}{ }_{1}-x_{i}\right) / H^{*}{ }_{1}$ & $G_{i}\left(D^{*}{ }_{2}-\mathbf{x}_{\mathbf{i}}\right) / \mathbf{H}_{2}^{*}$ & $\mathrm{G}_{\mathrm{i}}\left(\mathrm{D}^{*}{ }_{3}-x_{i}\right) / \mathrm{H}^{*}{ }_{3}$ & $G_{i}\left(D^{*}{ }_{4}-x_{i}\right) / H^{*}{ }_{4}$ \\
\hline 0 & 93.75 & 47.68 & 54.06 & 59.21 & 65.60 \\
\hline 1 & 30.78 & 14.89 & 16.86 & 18.43 & 20.33 \\
\hline 2 & 39.84 & 18.04 & 20.88 & 22.84 & 24.37 \\
\hline 3 & 45.74 & 19.32 & 21.77 & 23.70 & 25.77 \\
\hline 4 & 53.03 & 20.82 & 23.40 & 25.40 & 27.39 \\
\hline 5 & 60.94 & 21.94 & 24.58 & 26.58 & 28.34 \\
\hline 6 & 68.85 & 22.88 & 25.54 & 27.51 & 29.00 \\
\hline 7 & 82.26 & 25.03 & 27.83 & 29.84 & 31.01 \\
\hline 8 & 87.34 & 24.16 & 26.73 & 28.50 & 29.10 \\
\hline 9 & 90.26 & 22.44 & 24.67 & 26.13 & 26.08 \\
\hline 10 & 108.19 & 23.89 & 26.07 & 27.37 & 26.52 \\
\hline 11 & 111.13 & 22.54 & 24.45 & 25.48 & 24.08 \\
\hline 12 & 114.07 & 21.67 & 23.38 & 24.23 & 22.40 \\
\hline 13 & 121.47 & 21.73 & 23.32 & 24.02 & 21.72 \\
\hline 14 & 119.28 & 18.57 & 19.68 & 19.95 & 16.96 \\
\hline 15 & 137.49 & 18.23 & 18.97 & 18.83 & 14.52 \\
\hline 16 & 129.59 & 14.27 & 16.80 & 14.57 & 9.89 \\
\hline 17 & 134.15 & 11.85 & 12.70 & 11.80 & 6.30 \\
\hline 18 & 150.05 & 11.96 & 11.45 & 10.10 & 3.32 \\
\hline 19 & 140.20 & 8.81 & 7.94 & 6.32 & / \\
\hline 20 & 152.64 & 6.76 & 5.34 & / & / \\
\hline 21 & 152.64 & 4.58 & 2.80 & / & / \\
\hline 22 & 159.66 & 3.42 & 1.33 & / & / \\
\hline 23 & 166.66 & / & / & / & / \\
\hline
\end{tabular}

The four kinematical thrusts corresponding to the assumed positions of the internal hinge, respectively, are

$$
\begin{aligned}
& \sum G_{i}\left(D *_{1}-x_{i}\right) / H *_{1}=425.48 t \\
& \sum G_{i}\left(D *_{2}-x_{i}\right) / H *_{2}=460.64 t \\
& \sum G_{i}\left(D *_{3}-x_{i}\right) / H *_{3}=470.81 t \\
& \sum G_{i}\left(D *_{4}-x_{i}\right) / H *_{4}=452.70 t
\end{aligned}
$$

Other choices of the positions of the internal hinges give lower values. The maximum of the kinematical thrust in the slice reaches a value of $470.8 \mathrm{t}$, corresponding to position 3 of the hinge $\mathrm{O}$. With a previous calculation of the thrust performed by means of the statical approach, i.e., with the construction of a sequence of funicular polygons, a value of $400 \mathrm{t}$ was obtained in [16] (pp. 260-261). This last value, because of the approximations inherent the funicular polygon layout, can be considered less accurate than the value of $470.8 \mathrm{t}$ obtained by the kinematical approach.

In conclusion, the value of $470.8 \mathrm{t}$ can be considered the actual value of the minimum thrust conveyed by a single slice equal to $1 / 8$ of the Dome.

Averaging the lengths of the crown boundaries in which the drum is inscribed, assuming a circumferential length at the Dome springing equal to $\pi \cdot 0.5 \times(27.08 \times 2+20.77 \times 2)$ $=150.32 \mathrm{~m}$, the length of the base slice is $150.32 / 8=18.79 \mathrm{~m}$ and the unit minimum thrust 
for single meter of the circumferential length of the Dome springing circle is $470.8 / 18.79=$ $25 \mathrm{t} / \mathrm{mL}$. This value is remarkably less than the thrusts of St Peter's dome in Rome that reaches a value of about $30 \mathrm{t} / \mathrm{mL}$ [29] (pp. 981-990).

\section{Loads Conveyed to the Pillar}

The four pillars sustain all the weight of the dome. The pillars are directly charged at a height of $59 \mathrm{~m}$ by the weight of the webs directly overlying them. The weight of the webs overlying the arches are conveyed to the pillars following the stress flow shown in Figure 10 and reaches them at a height of $39 \mathrm{~m}$.

\subsection{Vertical Forces}

1. At a height of $52.00 \mathrm{~m}$ (dome basement elevation)

The vertical load $V_{52}$ stands for the weight of the web directly above the pillar, including the weight of the lantern slice. Thus, summing the weights $G_{i}$ of the ashlars composing the slice, according to the values given in Table 1 ,

$$
V_{52}=3575 t
$$

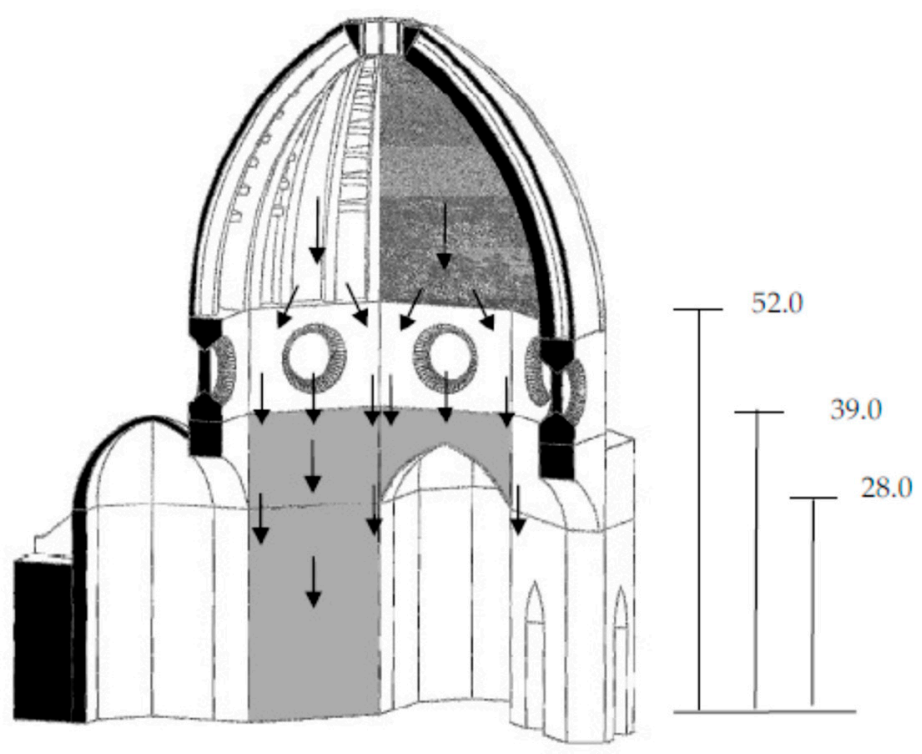

Figure 10. The web overlying the pillar and two half-webs above the adjacent arches.

2. At a height of $39.00 \mathrm{~m}$ (drum basement elevation)

The following loads have to be added to $V_{52}$ :

The weight $G_{\text {haw }}$ of the two halves of the adjacent webs overlying the arches.

$$
G_{t h w}=3575 t
$$

This weight is conveyed to the pillar at this height because it is deviated by the presence of "eyes" in the drum (Figure 10). The diameter of the "eye" is equal to $5.8 \mathrm{~m}$.

The weight $G_{u s d}$ of the upper segment of the drum directly overlying the pillar.

Length of the external side of the drum: $\mathrm{L}_{\mathrm{e}}=20.67 \mathrm{~m}$.

Length of the internal side of the drum: $\mathrm{L}_{\mathrm{e}}=17.21 \mathrm{~m}$.

Thickness of the sides of the drum: $\mathrm{T}_{\mathrm{h}}=4.18 \mathrm{~m}$.

Height of the upper part of the drum: $\mathrm{h}=13.0 \mathrm{~m}$.

$\mathrm{G}_{\mathrm{usd}}=0.5 \times(20.67+17.21) \times 13.0 \times 4.18 \times 2.2-\pi \times 5.8^{2} \times 4.18 \times 2.2 / 4=2264-243=2021 t$ 
Summing up all the various contributions, we get

$$
V_{39}=V_{52}+G_{t h w}+G_{u s d}=3575+3575+2021=9171 t
$$

3. At a height of $28.00 \mathrm{~m}$ (elevation of the springers of the pointed arches)

The following loads have to be added to $V_{39}$ :

The weight $G_{\text {thd }}$ of the two halves of the adjacent segments of the upper drum, conveyed by the adjacent pointed arches

$$
G_{\text {thd }}=2021 t
$$

The weight $V_{a a}$ of the two halves of the two adjacent arches.

This weight $V_{a a}$ can be evaluated by making reference to a simplified scheme of the geometry of the arch. With reference to Figure 11, the two components $V_{1}$ and $V_{2}$ of the arch give

$$
\begin{gathered}
V_{1}=10.00 \cdot 7.5 \cdot 0.5 \cdot 4.18 \cdot 2.2=345 t \quad d_{1}=3.33 \mathrm{~m} \\
V_{2}=10.0 \cdot 3.50 \cdot 4.18 \cdot 2.2=322 t \quad \mathrm{~d}_{2}=5.00 \mathrm{~m}
\end{gathered}
$$

The weight of the two halves of the adjacent pointed arches is

$$
V_{a a}=2\left(V_{1}+V_{2}\right)=2(345+322)=1334 t
$$

Summing up all the various contributions, we get

$$
V_{28}=V_{39}+G_{t h d}+V_{a a}=9297+2021+1334=12,652 t
$$

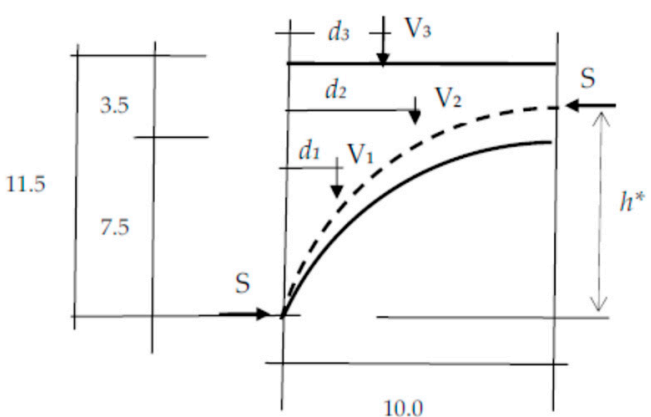

Figure 11. Scheme of the pointed arch.

\subsection{Horizontal Forces}

1. At a height of $52.00 \mathrm{~m}$, the resultant radial thrust delivered by webs is (Figure 12)

$$
S_{R w 52}=470.8+666=1136 t .
$$




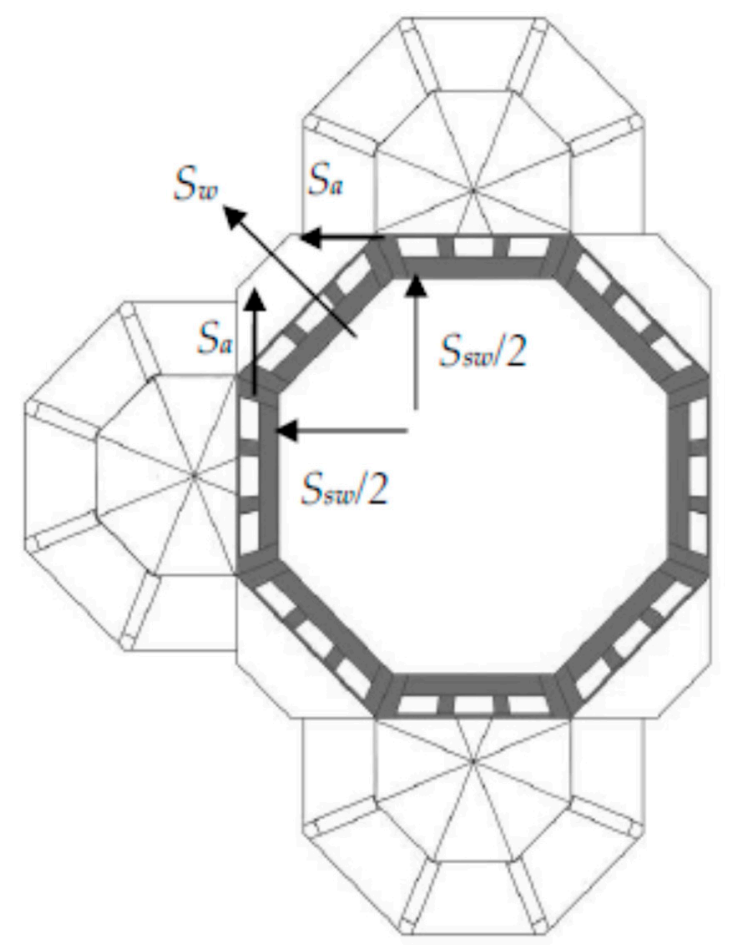

Figure 12. Composition of thrusts acting on the single pillar.

2. At a height of $28.00 \mathrm{~m}$ The vector sum $S^{\prime}{ }_{v a 28}$ of the thrusts $S_{a 28}$ of the two adjacent pointed arches. The thrust $S_{a 28}$.

The pointed arches are loaded, in addition to their weight, by the weight of the segment of the drum directly overlying them. The presence of these loads activates the thrust in these pointed arches. They are inserted between the four large pillars supporting the dome. No cracks have been detected at the intrados of these arches, as described in [5] (Figure 7, p. 413).

The assessment of the thrust in these pointed arches is difficult to evaluate. The presence of the minimum thrust state in the arches has to be excluded; their thrust will be included between their minimum and maximum values. In the case of the minimum thrust, the $\operatorname{arm} h^{*}$ of the thrust couple has a length of $11.5 \mathrm{~m}$. We assume a lower length of $h^{*}$ equal to $h^{*} 9.25 \mathrm{~m}$, as shown in Figure 11 .

With reference to Figure 11, the two components $V_{1}$ and $V_{2}$ of the arch weight are

$$
\begin{gathered}
V_{1}=10.0 \times 7.5 \times 0.5 \times 4.18 \times 2.2=345 t \quad d_{1}=3.33 \mathrm{~m} \\
V_{2}=10.0 \times 3.5 \times 4.18 \times 2.2=322 t \quad d_{2}=5.00 \mathrm{~m} \\
V_{3}=10.0 \times 13.0 \times 4.18 \times 2.2-\pi \times 5.8^{2} / 4=1074 t \quad d_{3}=5.30 \mathrm{~m}
\end{gathered}
$$

The equilibrium condition of half of the arch gives

$$
S_{a 28} \cdot 9.25=V_{1} \cdot d_{1}+V_{2} \cdot d_{2}+V_{3} \cdot d_{3}=1195 \cdot 4.60+322 \cdot 5.00+345 \cdot 3.33
$$

and the thrust of the pointed arch is

$$
S_{a 28}=\frac{1}{9.25}(4940+1610+1148)=832 t
$$

and acts at a height of $28 \mathrm{~m}$ from ground level.

The vector sum $S_{v a 28}^{\prime}$ is thus $S_{v a 28}^{\prime}=832 x \sqrt{2}=1176 t$ 
In conclusion, while at a height of $52.00 \mathrm{~m}$, the resultant radial thrust delivered by webs is $S_{R w 52}=470.8+\sqrt{2} 470.8=1136 \mathrm{t}$, at a height of $28 \mathrm{~m}$, the resultant thrust $S^{\prime}{ }_{v R a 28}$ of the pointed arches spanning between the arches is $S^{\prime}{ }_{v R a 28}=1176 \mathrm{t}$.

\section{Stresses at the Pillar Base}

The analysis concerns the two absidal piers even if analogous results can be obtained for the other two piers flanking the nave. At the pillar head $(h=28.0 \mathrm{~m})$,

$$
N_{28}=12,652 t
$$

The load $N_{28}$ is directed along the vertical axis passing through the center of the trapeze section of the single side segment of the octagonal crown. This section, part of the whole cross section of the pillar and sustaining a side of the drum, directly carries the load $N_{28}$. The area of this section equals about $1 / 2(20.67+17.21) 0.5=79.2 \mathrm{~m}^{2}$ and the corresponding compression stress is $12,652 / 79.2=16 \mathrm{~kg} / \mathrm{cm}^{2}$.

1. Section of the pillar

The pillar cross section is hollow in the center, up to a height of $20.0 \mathrm{~m}$, while it is solid from a height of $20.00 \mathrm{~m}$ up to $28.00 \mathrm{~m}$.

The masonry structure of the pillar is made up of about $2.0 \mathrm{~m}$ thick stone facings, tightly bound to a rubble and mortar core.

All the various dimensions of the section have been taken from documents and drawings and processed via a computer. The hollow section is shown in Figure 13.

The area $\mathrm{A}$ of the base section (hollow) and the distances of the center from its external sides (Figure 13) are

$$
\mathrm{A}=2,264,890 \mathrm{~cm}^{2} ; Y_{g s}=609.5 \mathrm{~cm} ; Y_{g i}=957.3 \mathrm{~cm}
$$

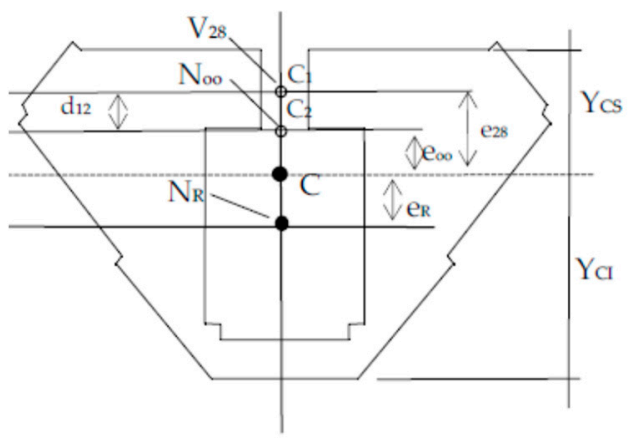

Figure 13. Position of the pillar hollow section center.

The moment of inertia $J_{x}$ of the section with respect to the central axis $x$, orthogonal to the symmetry axis $y$, is:

$$
J_{x}=3.98 \cdot 10^{11} \mathrm{~cm}^{4} .
$$

The distances of the core points from the section center $\mathrm{C}$ are

$$
d_{\text {sup }}=\frac{W_{i}}{A}=\frac{J_{x}}{A \cdot Y_{g i}}=188.6 \mathrm{~cm} \cdot d_{\text {inf }}=\frac{W_{s}}{A}=\frac{J_{x}}{A \cdot Y_{g s}}=290.5 \mathrm{~cm}
$$

2. Pillar weight

The weight $W_{P 0-20}$ of the segment of the pillar from the height $0.00 \mathrm{~m}$ up to $20.00 \mathrm{~m}$ : Area of the hollow section: $A=226.5 \mathrm{~m}^{2}$.

$W_{P} 0-20=226.5 \times 20.00 \times 2.2=9966 t$, by assuming the unit weight of the masonry of the pier equal to $2.2 \mathrm{t} / \mathrm{mc}$.

The weight $W_{P} 20-28$ of the segment of the pillar from the height $20.00 \mathrm{~m}$ up to $28.00 \mathrm{~m}$ : 
The cross section $A^{\prime}$ of this segment of the pier is solid. $\mathrm{A}^{\prime}=226.5 \mathrm{~m}^{2}+90 \mathrm{~m}^{2}=316 \mathrm{~m}^{2}$.

$$
W_{P 20-28}=: 316 \times 8.00 \times 2.2=5562 \mathrm{t}
$$

Total pillar weight: $W_{\text {pill }}=9966 \mathrm{t}+5562 \mathrm{t}=15,528 \mathrm{t}$.

3. Stresses at the pillar base section

Axial load:

The axial load $N_{o o}$ at the pillar base is obtained by summing the various vertical forces transmitted with the weight of the pillar:

$$
N_{o o}=V_{28}+W_{\text {pill }}=12,652+15,528=28,180 t
$$

Eccentricities of the various vertical loads conveyed to the pillar with respect to the center $\mathrm{C}$ of its base section:

A force of $V_{28}=12,652 t$ is conveyed through the side segment of the octagonal drum section, at a distance of $\mathrm{d}_{28}=1 / 24.18 \mathrm{~m}=2.09 \mathrm{~m}$ from the internal boundary of the crown.

With reference to Figure 13 , the corresponding eccentricity $e_{28}$ of the force $V_{28}=12,652 t$ is:

$$
e_{28}=\mathrm{Y}_{\mathrm{CS}}-2.09=6.09-2.09=4.00 \mathrm{~m} \text {. }
$$

The weight of the pillar $W_{\text {pill }}=15,528 t$ passes through the center of the hollow section. Thus, the following equation gives the eccentricity $e_{o o}$ of the resultant force $N_{o o}$ :

$12,652 \cdot 4.00=28,180 \cdot e_{o o}$ and $e_{o o}=1.8 \mathrm{~m}$. The eccentric load $N_{o o}=28,306 t$ acts outwards at the distance $e_{0 o}=1.8 \mathrm{~m}$ from the center $\mathrm{C}$ of the section (Figure 13).

Bending moments:

Vertical cracks cross all of the body of the drum, as shown in Figure 7 on page 413 of [5]. The drum has lost its hooping function. Brunelleschi concentrically inserted in the dome, at the level of first, second and third galleries, three girdling belts of "pietra di macigno", a strong sandstone, cramped by iron brackets.

A wood chain, made of wood lintels, connected by iron clamps, was also inserted over the first stone chain. All these chains are very deformable and can sustain only negligible shares of the dome thrust. Consequently, both the resultant radial thrust $S_{R w 52}$ conveyed by webs at a height of $52 \mathrm{~m}$ and the resultant radial thrust $S_{R a 28}$ conveyed by the arches at a height of $28 \mathrm{~m}$ push against the underlying pillar. The moment at the pillar base due to the thrusts is:

$M_{o o}=1136.8 \times 52+1176 \times 28=92,146 \mathrm{tm}$ and is directed outside.

4. Stresses in the pillar base section

The composition of the bending moment $M_{\mathrm{oo}}$ with the eccentric load $N_{o o}=28,180 \mathrm{t}$ yields a resultant eccentric load $N_{R}$ having a total eccentricity $e_{R}=1.82-92,146 / 28,180$ $=1.82-3.27=-1.45 \mathrm{~m}$ outside (Figure 13). The pier section is wholly compressed. The maximum and minimum compression stresses are:

$$
\begin{aligned}
& \sigma_{\text {ext }}=\frac{N}{A}+\frac{M}{J_{x}} Y_{g s}=\frac{28,180,000}{2,264,890}+\frac{28,180,000 \cdot 145}{3.98 \cdot 10^{11}} 957.3=12.44+9.83=22.3 \mathrm{~kg} / \mathrm{cm}^{2} \\
& \sigma_{\text {int }}=\frac{N}{A}-\frac{M}{J_{x}} Y_{g i}=\frac{28,180,000}{2,264,890}-\frac{28,180,000 \cdot 143}{3.98 \cdot 10^{11}} 609.5=12.50-6.2=6.3 \mathrm{~kg} / \mathrm{cm}^{2}
\end{aligned}
$$

The stress analysis reported in [5] (p. 421) gives a lower value of $15.4 \mathrm{~kg} / \mathrm{cmq}$ for the maximum compression stress in the pillar section at ground level. This difference can be explained considering that, in the model [5], the supporting structure of the dome also takes into account the structure of the side apses. The compressive stresses are sufficiently moderate to be sustained safely by the masonry, built with blocks of sandstone (pietra forte) and good mortar.

The expansion of the base of the dome, due to the occurrence of the two major cracks (type A in [5]) of a width of about $6 \mathrm{~cm}$, involves a radial displacement of the dome base of 
about $6.0 \mathrm{~cm} / \pi=1.9 \mathrm{~cm}$. This displacement can be in full agreement with the visco-elastic flexure of the piers and of their foundations.

It is worth further remarking that the slow creep deformations occurring in the piers and in their foundations could explain the detected slow increase over time of the width of the major cracks in the webs, estimated, on average, to be about $5.5 \mathrm{~mm} /$ century [22] (p. 50).

\section{Conclusions and Results}

The estimate of the thrust of Brunelleschi's Dome in Florence and of the consequent stresses in the sustaining piers is the subject of the paper. After a brief description of the Dome and its damage state, the paper first explained the reasons for the insurgence of thrust in rotational masonry domes. The same occurred in Brunelleschi's Dome. The detected crack patterns reveal a rotational behavior of the dome, in spite of its external appearance of a segmental cloister vault, due to the clever constructional devices of Brunelleschi.

Useful in this context is the application of the kinematical approach, first studied by the author $[14,15]$ in the framework of the Heyman model of masonry behavior. The basic principles of this approach are first recalled and then applied to the assessment of the thrust of Brunelleschi's Dome. The thrust has been evaluated by making reference to a Dome slice equal to $1 / 8$ of the entire dome, a single web that is directly supported by the underlying pier. The minimum thrust of the slice has thus been obtained as the maximum of all the kinematical ones. This maximum reaches a value of $470.8 \mathrm{t}$, corresponding to $25 \mathrm{t} / \mathrm{mL}$ for a meter of the dome springing circle. This value is larger than the value of $21.3 \mathrm{t} / \mathrm{mL}$ obtained by applying the statical approach to the Dome, a less accurate procedure using the construction of sequences of funicular polygons.

The base section of the underlying pillars is eccentrically compressed, and the level of stresses is sufficiently low. Small rotations of the basement of the piers, due to the development of limited creep deformation of the underlying soil, the gravel of the River Arno, can account for the detected very slow increase over time of the width of the major cracks in the dome webs.

Over the centuries, the dome has largely maintained a stable configuration and stands as one of the most extraordinary examples of the soundness and beauty of Renaissance architecture. This result is due to the extraordinary dome design of Filippo Brunelleschi and to the smart plan of the pillar section, with the favorable positioning of the drum, perhaps due to Arnolfo di Cambio or to the succeeding Masters, such as Talenti, Lapo di Ghini and Neri di Fioravanti.

Funding: This research received no external funding.

Institutional Review Board Statement: Not applicable.

Informed Consent Statement: Not applicable.

Data Availability Statement: Not applicable.

Conflicts of Interest: The authors declare no conflict of interest.

\section{References}

1. Heyman, J. The Stone Skeleton. Int. J. Solids Struct. 1966, 2, 249-279. [CrossRef]

2. Como, M. Equilibrium and Collapse of Masonry Bodies. In Masonry Constructions; Calladine, C.R., Ed.; Kluwer Academic Press: Dordrecht, The Netherlands, 1992; Volume 27, pp. 185-194.

3. Como, M. Virtual Displacement Principle, Existence and Uniqueness for Elastic no Tension Bodies. Meccanica 2017, 52, 1397-1405. [CrossRef]

4. Bartoli, G. Edifici Monumentali: Monitoraggio e Modellazioni numeriche. In Proceedings of the Il Monitoraggio Delle Grandi Fabbriche Storiche, Firenze, Italy, 19-20 January 2012; Mandragora: Firenze, Italy, 2012; pp. 108-111.

5. Bartoli, G.; Betti, M.; Borri, C. Numerical Modelling of the Structural behavior of Brunelleschi's Dome of Santa Maria del Fiore. Intern. J. Archit. Herit. 2015, 9, 408-428. [CrossRef]

6. Betti, M.; Drosopoulos, G.A.; Stavroulakis, G.E. Two nonlinear finite element models developed for the assessment of failure of masonry arches. Comptes Rendus Mec. 2008, 336, 42-53. [CrossRef] 
7. Chiarugi, A.; Bartoli, G.; Bavetta, F. La meccanica della Cupola. In La Cupola di Santa Maria del Fiore-Il Cantiere di Restauro 1980-1995; Istituto Poligrafico e Zecca della Stato: Rome, Italy, 1995; pp. 47-62.

8. Betti, G.; Bartoli, G.; Borri, C. Filippo Brunelleschi and the Dome of Santa Maria del Fiore. In Developments and Applications in Computational Structures Technology; Topping, B.H.V., Ed.; Saxe-Coburg Publ.: Stirling, UK, 2010; pp. $309-327$.

9. Bartoli, G.; Betti, M.; Blasi, C.; Ottoni, F.; Coli, M.; Marchetti, E.; Ripepe, M. Synergetic interdisciplinary Approaches for the Conservation of Monumental Heritage: Cupola of Santa Maria del Fiore in Florence. J. Perform. Constr. Facil. 2012, 30, 04015091. [CrossRef]

10. Lourenco, P.B. Structural Analysis of Historical Constructions: Possibilities Numerical and Experimental Techniques; Macmillan: New Delhi, India, 2006.

11. Milani, G.; Lourenco, P.B. Modelling Masonry with Limit Analysis Finite Elements: Review, applications and new directions. In Civil Engineering Computations: Tools and Techniques; Topping, B.H.V., Ed.; Saxe-Coburg Publ.: Stirling, UK, 2007 ; pp. $217-242$.

12. Lourenco, P.B. Recent Advances in Modelling Masonry Shells: Validation and Applications. In Structural Engineering and Mechanics; Choi, C.K., Ed.; Techno-Press: Taejon, Korea, 1999; pp. 1247-1252.

13. Heyman, J. Domes. In The Stone Skeleton, Structural Engineering of Masonry Architecture; Cambridge University Press: Cambridge, UK, 1995; pp. 27-47.

14. Como, M. On the role played by Settlements in the Statics of masonry Structures. In Proceedings of the International Symposium of Geotechnical Engineering for the Preservation of Monuments and Historic Sites, Naples, Italy, 3-4 October 1996; A.A. Balkema: Rotterdam, The Netherlands, 1997; pp. 8-87.

15. Como, M. Minimum and Maximum Thrust States in Statics of Ancient Masonry Buildings. In Proceedings of the Second International Arch Bridge Conference, Venice, Italy, 6-9 October 1998; Sinopoli, A., Ed.; A.A. Balkema: Rotterdam, The Netherlands, 1998; pp. 133-137.

16. Como, M. Domes. Statics of Historic Masonry Constructions; Fremond, M., Maceri, F., Eds.; Springer Series in Solid and Structural Mechanics; Springer: Cham, Switzerland, 2017.

17. Mainstone, R.J. Brunelleschi's Dome of S. Maria del Fiore and some Related Structures. Trans. Newcom. Soc. 1969, 42, 124-150. [CrossRef]

18. Di Pasquale, S. La soluzione Brunelleschiana. In Brunelleschi: La Costruzione Della Cupola di Santa Maria del Fiore; Marsilio: Venezia, Italy, 2002; pp. 71-160.

19. Ippolito, L.; Peroni, C. La Cupola di Santa Maria del Fiore; La Nuova Italia Scientifica: Firenze, Italy, 1997.

20. Como, M.T. Structural Devices concerning the Progressive Outer Shell Construction in Brunelleschi Dome. In Nuts and Bolts of Construction History Culture, Technology and Society; Caravais, R., Guillerme, A., Nègre, V., Sakarowitch, J., Eds.; Picard: Paris, France, 2012; Volume 1, pp. 331-339.

21. Ottoni, F. Delle Cupole e del Loro Tranello, la Lunga Vicenda Delle Fabbriche Cupolate tra Dibattito e Sperimentazione; Aracne: Rome, Italy, 2012.

22. Blasi, C. Sessant'anni di monitoraggio della cupola di Santa Maria del Fiore. In Proceedings of the Il Monitoraggio Delle Grandi Fabbriche Storiche, Firenze, Italy, 10-20 January 2012; Mandragora: Firenze, Italy, 2012; pp. 41-53.

23. Blasi, C.; Ceccotti, A. La Cupola del Brunelleschi: Indagine sullo stato di fessurazione. In Proceedings of the INARCOS Ingegneri Architetti Costruttori, Bologna, Italy, 5-7 June 1984; pp. 228-236.

24. Blasi, C.; Coisson, E.; Ottoni, F. The crack pattern in Brunelleschi's dome in Florence. Damage evolution from historical to modern monitoring system analysis. Adv. Mater. Res. 2010, 133, 53-64.

25. Guerrieri, F. La cupola di Santa Maria del Fiore e il suo sistema di monitoraggio. In Proceedings of the Il Monitoraggio Delle Grandi Fabbriche Storiche, Firenze, Italy, 10-20 January 2012; Mandragora: Firenze, Italy, 2012; pp. 31-39.

26. Coulomb, C.A. Essai sur une application des règles de maximis \& minimis à quelques problèmes de statique, relatifs à l'architecture. In Mémoires de Mathématique et de Physique, Présentés à l'Académie Royale des Sciences par Divers Savans; 1773; Reprinted in Théorie des Machines Simples; Bachelier: Paris, France, 1821; Volume 7.

27. Heyman, J. Coulomb Memoir on Statics, An Essay in the History of Civil Engineering; Cambridge University Press: Cambridge, UK, 1972; pp. 41-74.

28. Como, M. Un antico restauro statico della cupola di S. Pietro in Roma. In Lo Specchio del Cielo; Conforti, C., Ed.; Electa: Milano, Italy, 1997; pp. 245-260.

29. Como, M. Sulla storia del restauro statico della cupola di S. Pietro in Roma eseguito da Poleni e Vanvitelli. In Proceedings of the 2nd Convegno di Storia dell'Ingegneria, Napoli, Italy, 7-9 April 2008; Cuzzolin: Napoli, Italy, 2008; pp. 981-990. 